\title{
Article
}

\section{Red Blood Cell Transfusion in the Emergency Department: An Observational Cross-Sectional Multicenter Study}

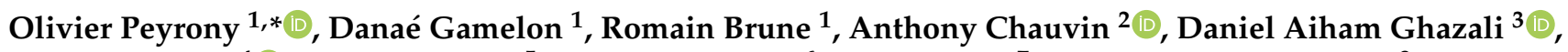 \\ Youri Yordanov ${ }^{4}{ }^{\circ}$, Aude Arsicaud ${ }^{5}$, Pauline Gilleron ${ }^{6}$, Sonja Curac ${ }^{7}$, Marie-Caroline Richard ${ }^{8}$, \\ Anne-Laure Feral-Pierssens ${ }^{9}$, Barbara Villoing ${ }^{10}$, Sébastien Beaune ${ }^{11}{ }^{10}$, Hélène Goulet ${ }^{12}$, Jean-Paul Fontaine ${ }^{1}$, \\ Anne François ${ }^{13}$ and France Pirenne ${ }^{14}$
}

check for updates

Citation: Peyrony, O.; Gamelon, D.; Brune, R.; Chauvin, A.; Ghazali, D.A.; Yordanov, Y.; Arsicaud, A.; Gilleron, P.; Curac, S.; Richard, M.-C.; et al. Red Blood Cell Transfusion in the Emergency Department: An Observational Cross-Sectional Multicenter Study. J. Clin. Med. 2021, 10, 2475. https://doi.org/10.3390/ jcm10112475

Academic Editor: Young-Lan Kwak

Received: 3 May 2021

Accepted: 31 May 2021

Published: 2 June 2021

Publisher's Note: MDPI stays neutral with regard to jurisdictional claims in published maps and institutional affiliations.

Copyright: (c) 2021 by the authors. Licensee MDPI, Basel, Switzerland. This article is an open access article distributed under the terms and conditions of the Creative Commons Attribution (CC BY) license (https:// creativecommons.org/licenses/by/ $4.0 /)$.
1 Emergency Department, Hôpital Saint-Louis, Assistance Publique-Hôpitaux de Paris, 1 Avenue Claude Vellefaux, 75010 Paris, France; danaegamelon@gmail.com (D.G.); romain.brune@gmail.com (R.B.); jean-paul.fontaine@aphp.fr (J.-P.F.)

2 Emergency Department, Hôpital Lariboisière, Assistance Publique-Hôpitaux de Paris, 75010 Paris, France; anthony.chauvin@aphp.fr

3 Emergency Department, Hôpital Bichat, Assistance Publique-Hôpitaux de Paris, 75018 Paris, France; danielaiham.ghazali@aphp.fr

4 Emergency Department, Hôpital Saint-Antoine, Assistance Publique-Hôpitaux de Paris, 75012 Paris, France; youri.yordanov@aphp.fr

5 Emergency Department, Hôpital André Mignot, 78300 Versailles, France; aude.arsicaud@gmail.com

6 Hôpital Henri Mondor, Assistance Publique-Hôpitaux de Paris, 94000 Créteil, France; pauline.gilleron@aphp.fr

7 Hôpital Beaujon, Assistance Publique-Hôpitaux de Paris, 92024 Clichy, France; sonja.curac@aphp.fr

8 Hôpital Pitié Salpetrière, Assistance Publique-Hôpitaux de Paris, 75013 Paris, France; Marie-caroline.richard@aphp.fr

9 Hôpital Européen Georges Pompidou, Assistance Publique-Hôpitaux de Paris, 75015 Paris, France; anne-laure.feral-pierssens@aphp.fr

10 Hôpital Cochin, Assistance Publique-Hôpitaux de Paris, 75014 Paris, France; barbara.villoing@aphp.fr

11 Hôpital Ambroise Paré, Assistance Publique-Hôpitaux de Paris, 92100 Boulogne, France; sebastien.beaune@aphp.fr

12 Hôpital Tenon, Assistance Publique-Hôpitaux de Paris, 75020 Paris, France; helene.goulet@aphp.fr

13 Etablissement Français du Sang Ile de France, 75010 Paris, France; anne.francois@efs.sante.fr

14 Etablissement Français du Sang Ile de France, Hôpital Henri Mondor, Assistance Publique-Hôpitaux de Paris, Université Paris Est Créteil, INSERM U955, Institut Mondor de Recherche Biomédicale, 94000 Créteil, France; france.pirenne@efs.sante.fr

* Correspondence: o.peyrony@hotmail.fr; Tel.: +33-1-42-49-84-04

Abstract: Background: We aimed to describe red blood cell (RBC) transfusions in the emergency department (ED) with a particular focus on the hemoglobin $(\mathrm{Hb})$ level thresholds that are used in this setting. Methods: This was a cross-sectional study of 12 EDs including all adult patients that received RBC transfusion in January and February 2018. Descriptive statistics were reported. Logistic regression was performed to assess variables that were independently associated with a pre-transfusion $\mathrm{Hb}$ level $\geq 8 \mathrm{~g} / \mathrm{dL}$. Results: During the study period, 529 patients received RBC transfusion. The median age was 74 (59-85) years. The patients had a history of cancer or hematological disease in 185 (35.2\%) cases. Acute bleeding was observed in the ED for $242(44.7 \%)$ patients, among which 145 (59.9\%) were gastrointestinal. Anemia was chronic in 191 (40.2\%) cases, mostly due to vitamin or iron deficiency or to malignancy with transfusion support. Pre-transfusion $\mathrm{Hb}$ level was 6.9 (6.0-7.8) g/dL. The transfusion motive was not notified in the medical chart in 206 $(38.9 \%)$ cases. In the multivariable logistic regression, variables that were associated with a higher pre-transfusion $\mathrm{Hb}$ level $(\geq 8 \mathrm{~g} / \mathrm{dL})$ were a history of coronary artery disease (OR: $2.09 ; 95 \% \mathrm{CI}$ : 1.29-3.41), the presence of acute bleeding (OR: 2.44; 95\% CI: 1.53-3.94), and older age (OR: 1.02/year; 95\% CI: 1.01-1.04). Conclusion: RBC transfusion in the ED was an everyday concern and involved patients with heterogeneous medical situations and severity. Pre-transfusion $\mathrm{Hb}$ level was rather restrictive. Almost half of transfusions were provided because of acute bleeding which was associated with a higher $\mathrm{Hb}$ threshold. 
Keywords: transfusion; red blood cell; blood product; anemia; hemoglobin; emergency department

\section{Introduction}

Blood products are scarce and valuable treatments that rely entirely on donors and should be administered judiciously. Moreover, improving transfusion practices may reduce the risk of adverse events such as pulmonary edema, hemolytic reactions, anaphylaxis, alloimmunization, and infection, among others. For this purpose, restrictive thresholds of hemoglobin $(\mathrm{Hb})$ levels are favored over liberal thresholds [1].

In 2014, the French National Authority for Health published guidelines for red blood cell (RBC) transfusion [2]. These recommendations defined RBC transfusion thresholds in limited contexts and settings such as anesthesiology, intensive care, and onco-hematology. Basically, a threshold of $7 \mathrm{~g} / \mathrm{dL}$ was recommended in the intensive care setting, in particular for patients with acute gastro-intestinal bleeding. This threshold could be increased to $10 \mathrm{~g} / \mathrm{dL}$ in cases of acute coronary syndrome or heart failure or in a patient with poor tolerance of anemia (e.g., tachycardia, altered mental status, hypotension, dyspnea). In patients with solid or hematological malignancies likely to have chronic anemia due to chemotherapy, chronic inflammation, or bone-marrow infiltration, the threshold was $8 \mathrm{~g} / \mathrm{dL}$ and $10 \mathrm{~g} / \mathrm{dL}$ in cases of poor tolerance. In elderly patients above 80 years of age, the threshold was $7 \mathrm{~g} / \mathrm{dL}$, and $8 \mathrm{~g} / \mathrm{dL}$ in case of history of heart failure or coronary artery disease, or $10 \mathrm{~g} / \mathrm{dL}$ in cases of poor tolerance. These thresholds could be increased in case of rapid onset of anemia.

More recently, an international consensus conference established evidence-based recommendations for RBC transfusion thresholds for adults [3]. Authors also recommended a restrictive $\mathrm{RBC}$ transfusion threshold of $7 \mathrm{~g} / \mathrm{dL}$ in critically ill but clinically stable intensive care patients, and of $7-8 \mathrm{~g} / \mathrm{dL}$ for hemodynamically stable patients with acute gastrointestinal bleeding although the quality of evidence was moderate to low. The lack of evidence did not allow the expert panel to recommend any threshold for patients with lower intestinal or non-gastro-intestinal acute bleeding, onco-hematologic or coronary heart diseases.

Very few studies were focused on RBC transfusion in the emergency department (ED). The majority of them focused on critically ill patients in the intensive care unit (ICU) or on specific situations such as gastro-intestinal bleeding or trauma [4-11].

In this study, we aimed at describing patients that were transfused with RBC in the ED with a particular focus on the $\mathrm{Hb}$ level thresholds used in this setting.

\section{Methods}

\subsection{Objectives}

The objectives of this study were to assess the pre-transfusion $\mathrm{Hb}$ level depending on patients' characteristics and determine which clinical characteristics were associated with a higher transfusion threshold in the ED.

\subsection{Study Design, Settings, and Participants}

We conducted an observational, multicenter, cross-sectional study in 12 EDs. All the centers were academic except one, and were located in, or near, Paris, France. The Etablissement Français du Sang (EFS) provided the list of all adult patients that received RBC transfusion, with the number of units, in those EDs from 1 January to 28 February 2018. The EFS is a public national organization that manages the collection, processing, and distribution of blood products, and guarantees the safety of the transfusion chain. Then we collected standardized data from patients' medical files in each center, including demographic data (age, sex); medical history and usual treatments; reasons for ED referral (some patients reported several symptoms); vital parameters at triage including $\mathrm{Hb}$ pointof-care testing (POCT) HemoCue if performed; life-threatening conditions (shock, dyspnea 
or altered mental status according to the attending emergency physician); acute bleeding in the ED; pre-transfusion $\mathrm{Hb}$ level, reticulocyte count at arrival and post-transfusion $\mathrm{Hb}$ level based on blood withdrawal; number of RBC packs transfused in the ED; adverse events related to the transfusion; length of hospital stay and status at hospital discharge (deceased or alive).

Bleeding risk included personal medication, low platelet count $\left(<50,000 / \mathrm{mm}^{3}\right)$, and digestive causes.

Hematological diseases included hematological malignancies and non-malignant diseases such as idiopathic thrombocytopenia and sickle cell disease.

Overtransfusion was defined by a post-transfusion $\mathrm{Hb}$ level $\geq 10 \mathrm{~g} / \mathrm{dL}$.

Patients were categorized into four different groups: upper gastrointestinal bleeding, lower gastrointestinal bleeding, non-gastrointestinal bleeding, and absence of bleeding.

\subsection{Analysis}

Descriptive statistics were reported, namely median with interquartile range (IQR) for continuous variables and number with percentage (taking into account missing data) for categorical variables with comparison based on the Mann Whitney test or the chi square test, respectively. Due to the retrospective design, some data were missing from the ED medical files.

To assess the concordance between the measure of pre-transfusion $\mathrm{Hb}$ by the $\mathrm{Hb}$ POCT at arrival and the laboratory complete blood count (CBC), we plotted a Bland and Altman graphic and computed the percentage error. The reticulocyte counts were compared depending on the presence or absence of acute bleeding observed in the ED. Pretransfusion $\mathrm{Hb}$ level was plotted depending on the presence or absence of acute bleeding or a life-threatening condition. In order to assess variables that were independently associated with a higher pre-transfusion $\mathrm{Hb}$ level, we first performed a bivariate analysis where the dependent variable was a pre-transfusion $\mathrm{Hb} \geq 8 \mathrm{~g} / \mathrm{dL}$. Then, variables that were associated to the dependent variable with a $p$-value $\leq 0.1$ were included in a multivariable logistic regression. In order to adjust the for patient's severity, the variables that referred to life-threatening conditions (such as shock, dyspnea, altered mental status) and tachycardia on arrival were forced into the model whatever their $p$-value was. A backward selection was performed and non-significant variables were removed. All $p$-values were two-sided, with values of 0.05 or less considered as statistically significant. Data were analyzed with $R$ 3.5.0 software (the R Foundation for Statistical Computing, Vienna, Austria).

\subsection{Ethical Aproval}

The study was approved by the Institutional Review Board of the Comite d'Evaluation de l’Ethique des projets de Recherche Biomédicale (CEERB) Paris-Nord n 2019-023.

\section{Results}

\subsection{General Characteristics, Reasons for ED Referral, and Physical Examination}

During the study period, 529 patients received RBC transfusion in the 12 participating EDs. That is, on average, 0.7 patients per day and per center. Those patients received 1101 RBC packs. The number of RBC packs transfused in the EDs accounted for $4.4 \%$ of the total RBC transfused in the participating hospitals during the study period $(25,567$ RBC packs). General characteristics are presented in Table 1. The median age was 74 (59-85) years and $277(52.4 \%)$ were females. The patients attended EDs during night shift (between 6 p.m. and 8 a.m.) in 185 (35.4\%) cases and were referred to the ED by a non-emergency physician in 289 (55.3\%) cases; mostly general physicians, laboratories, or nursing homes. When considering their medical history, 185 (35.2\%) patients had active or an history of cancer or hematological disease. Anemia was chronic and secondary to vitamin or iron deficiency, chronic digestive or gynecological bleeding, renal insufficiency or malignancy with iterative transfusion support in 191 (40.2\%) cases (54 missing data). Patients were 
considered at risk of bleeding in relation to medications in $238(45.5 \%)$ cases, thrombopenia $\left(<50,000 / \mathrm{mm}^{3}\right)$ in $63(12.9 \%)$ cases, and chronic gastro-intestinal lesion in $83(15.8 \%)$ cases.

Table 1. General characteristics of patients transfused with red blood cells in the ED.

\begin{tabular}{|c|c|c|c|}
\hline Variable & & & Missing Data \\
\hline$N$ & 529 & & \\
\hline Female gender, $n(\%)$ & 277 & (52.4) & 0 \\
\hline Age (years), median (IQR) & 74 & (59-85) & 0 \\
\hline Night shift (6 p.m.-8 a.m.), $n$ (\%) & 185 & (35.4) & 6 \\
\hline \multicolumn{4}{|l|}{ Medical history, $n(\%)$} \\
\hline None & 72 & (13.7) & 4 \\
\hline Hypertension & 235 & (44.8) & 4 \\
\hline Coronary artery disease & 144 & (27.5) & 4 \\
\hline Chronic heart failure & 74 & (14.1) & 3 \\
\hline Chronic pulmonary disease & 55 & (10.4) & 2 \\
\hline Renal insufficiency & 18 & (3.4) & 4 \\
\hline Iron or vitamin deficiency & 97 & (18.3) & 0 \\
\hline Solid malignancy & 109 & (20.7) & 3 \\
\hline Hematological malignancy & 69 & (13.4) & 4 \\
\hline Non-malignant hematological disease & 15 & $(2.9)$ & 4 \\
\hline Chemotherapy < 1 month, $n(\%)$ & 62 & (12.0) & 12 \\
\hline Iterative transfusions $n(\%)$ & 73 & (14.1) & 13 \\
\hline \multicolumn{4}{|l|}{ Bleeding risk, $n(\%)$} \\
\hline Medication & 238 & (45.6) & 7 \\
\hline Antiplatelet therapy & 135 & (25.9) & \\
\hline Vitamin $\mathrm{K}$ antagonist & 48 & $(9.2)$ & \\
\hline Direct oral anticoagulant & 38 & (7.3) & \\
\hline Heparin & 36 & (6.9) & \\
\hline Non-steroidal anti-inflammatory drug & 8 & (1.5) & \\
\hline Thrombopenia & 63 & (12.9) & 40 \\
\hline Other* & 83 & (15.8) & 3 \\
\hline Patient referred by, $n(\%)$ & 289 & (56.0) & 13 \\
\hline General practitioner & 97 & (18.8) & \\
\hline Laboratory & 72 & (14.0) & \\
\hline Nursing home care institution & 50 & (9.7) & \\
\hline Pre-hospital emergency service & 26 & (5.0) & \\
\hline Specialist & 17 & (3.3) & \\
\hline Other & 14 & (2.7) & \\
\hline
\end{tabular}

The main reasons for ED referral are summarized in Table 2. The two most frequent reasons were anemia in 191 (36.1\%) cases and bleeding in $187(35.3 \%)$ cases. Acute bleeding was actually observed in the ED for 242 (44.7\%) patients, among which 145 (59.9\%) were of gastrointestinal origin.

Patients had a life-threatening condition (dyspnea, shock or altered mental status) in $158(30.2 \%)$ cases, were tachycardic on arrival in $169(32.6 \%)$ cases or had a history of coronary artery disease in $144(27.5 \%)$ cases.

Pre-transfusion $\mathrm{Hb}$ level was 6.9 (6.0-7.8) g/dL (distribution is shown in Figure 1). The pre-transfusion $\mathrm{Hb}$ level (g/dL) was (7-8) for 119 (22.5\%) patients, (8-9) for $78(14.7 \%)$ patients, (9-10) for 17 (3.2\%) patients, and $\geq 10 \mathrm{~g} / \mathrm{dL}$ for $11(2.1 \%)$ patients.

At arrival, a Hb POCT was performed for 253 (47.8\%) patients among which 119 $(47 \%)$ were presenting acute bleeding. While Figure 2 seems to show a good concordance of the pre-transfusion $\mathrm{Hb}$ level between both measures ( $\mathrm{Hb}$ POCT vs. laboratory $\mathrm{CBC}$ ), the percentage error was $37 \%$. Twenty-two $(8.7 \%)$ patients had a difference $\geq 2 \mathrm{~g} / \mathrm{dL}$ between both measures. However, in $35(13.8 \%)$ cases, the $\mathrm{Hb}$ level was below $7 \mathrm{~g} / \mathrm{dL}$ with POCT while it was above with laboratory $\mathrm{CBC}$, and it was the opposite for $13(5.1 \%)$ patients (Figure 3). 
Table 2. Reasons for ED referral and clinical exams at arrival of patients transfused with red blood cells in the ED.

\begin{tabular}{cccc}
\hline Variables & & Missing Data \\
\hline $\boldsymbol{N}$ & 529 & & 0 \\
Reasons for ED referral, $\boldsymbol{n} \mathbf{( \% )}$ & & $(36.1)$ & 0 \\
Anemia & 191 & $(35.3)$ & 0 \\
Bleeding & 187 & $(29.5)$ & 0 \\
Fatigue & 156 & $(7.4)$ & 0 \\
Dizziness & 39 & $(6.0)$ & 0 \\
Thoracic pain & 37 & $(3.4)$ & 0 \\
Trauma & 32 & & 10 \\
Neurological disorders & 18 & $(32.6)$ & 6 \\
Physical examination, $\boldsymbol{n}$ (\%) & & $(19.3)$ & 4 \\
Tachycardia ( $\geq 100 /$ bpm) & 169 & $(10.9)$ & 5 \\
Dyspnea & 101 & $(6.1)$ & 3 \\
Shock & 57 & $(46.0)$ & 3 \\
Altered mental status & 32 & $(27.6)$ & 3 \\
Gastro-intestinal & 242 & $(5.5)$ & 3 \\
Cutaneous & 145 & $(4.2)$ & 3 \\
Mucosal * & 29 & $(4.0)$ & 3 \\
Genitourinary & 22 & $(3.2)$ & 3 \\
Urinary & 21 & $(0.6)$ & 3 \\
Peritoneal & 17 & $(0.6)$ & \\
Hemoptysis * & 3 & &
\end{tabular}

${ }^{*}$ One patient had both mucosal and hemoptysis.

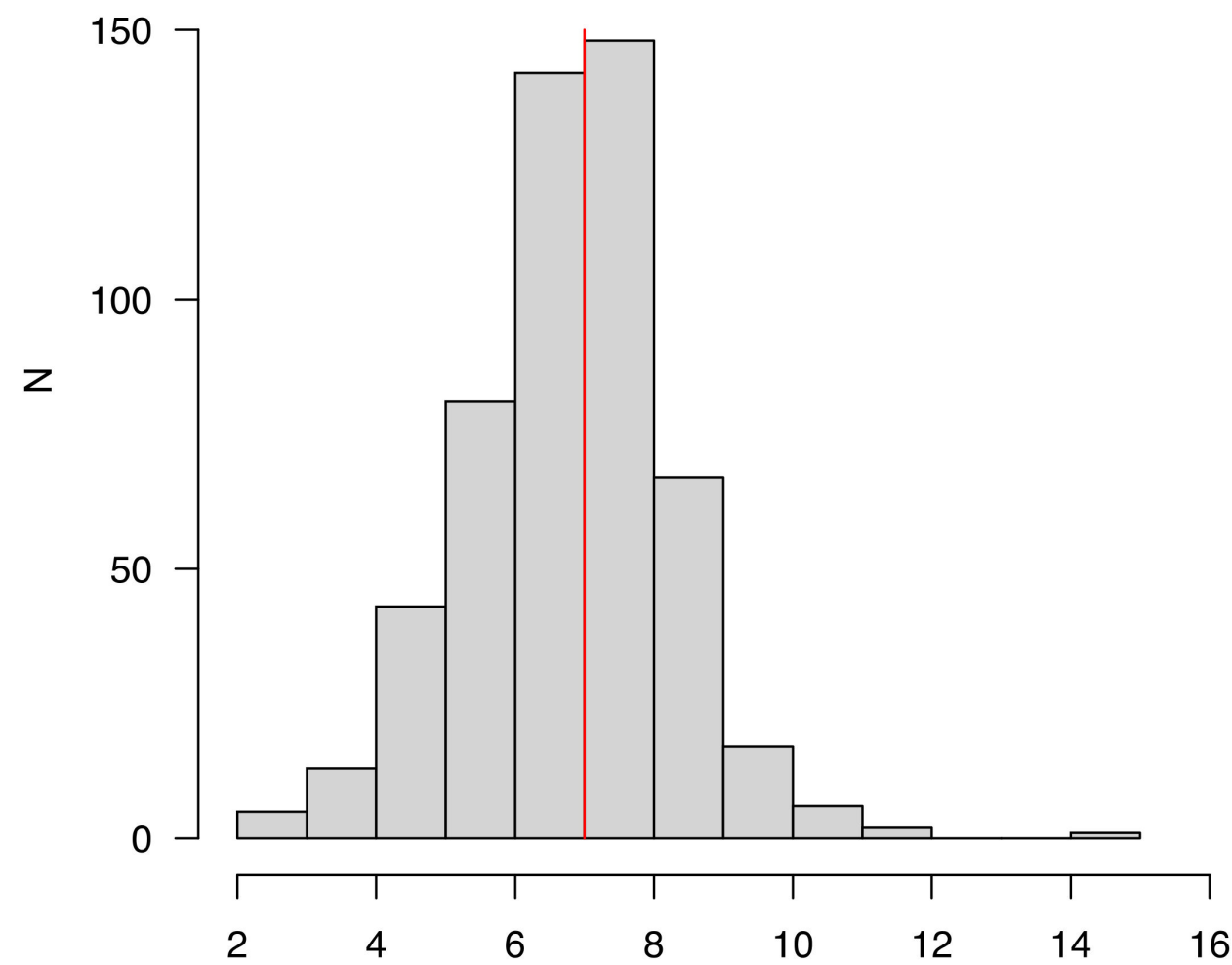

Pre-transfusion $\mathrm{Hb}$ level $(\mathrm{g} / \mathrm{dL}$ )

Figure 1. Histogram showing the distribution of the $\mathrm{Hb}$ level before transfusion $(N=529)$. 


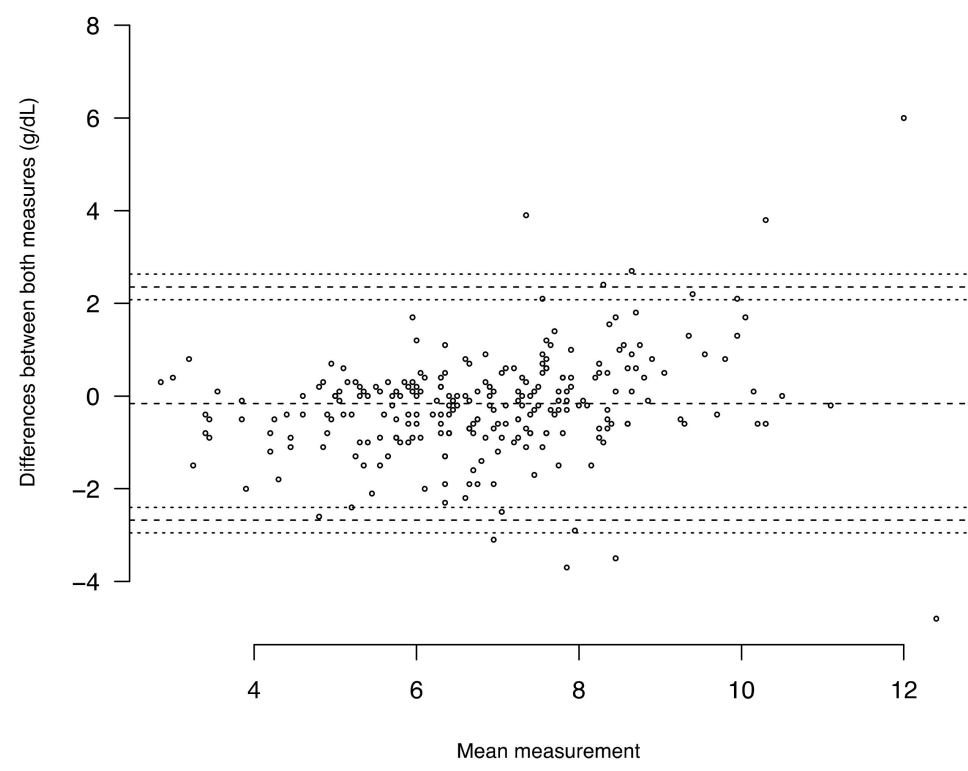

Figure 2. Concordance between pretransfusion $\mathrm{Hb}$ level $(\mathrm{g} / \mathrm{dL})$ depending on the measurement (point-of-care testing HemoCue vs. laboratory complete blood count with Bland and Altman graphic $(N=253)$. Each dot shows the difference between the 2 measurements for a patient over the mean of these 2 values. Dashed lines are the mean of the differences and the limits of agreement $(2$ standard deviations) above and below that. (The mean of the differences was $-0.16 \mathrm{~g} / \mathrm{dL}$ and the $2 \mathrm{SD}$ were $2.35 \mathrm{~g} / \mathrm{dL}$ and $-2.68 \mathrm{~g} / \mathrm{dL}$.) Dotted lines are the $95 \%$ confidence intervals of each limit of agreement $(2.63 ; 2.08 ;-2.40 ;-2.95)$.
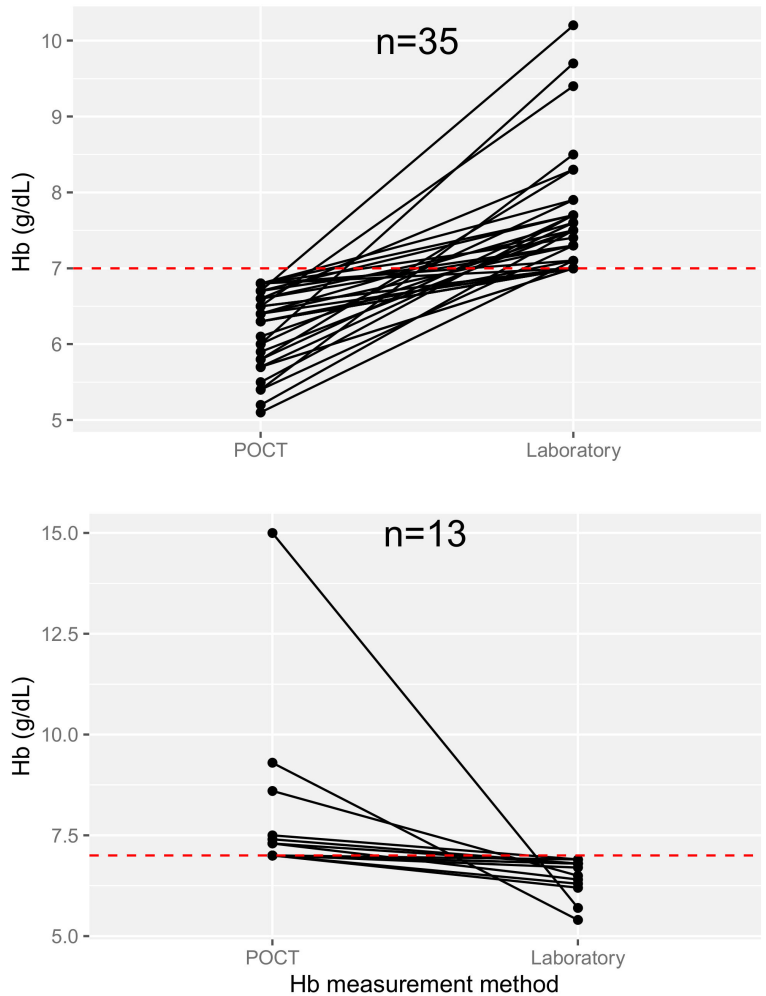

Figure 3. Discordances between pretransfusion $\mathrm{Hb}$ level ( $\geq$ or $<7 \mathrm{~g} / \mathrm{dL}$ ) depending on the measurement method (point-of-care testing vs. laboratory complete blood count). 
A reticulocyte count was performed in $251(47.4 \%)$ patients. Reticulocytes were $73,000(47,282-101,000) / \mathrm{mm}^{3}$ when bleeding was observed, whereas they were 51,700 $(31,000-84,000) / \mathrm{mm}^{3}$ in the absence of bleeding (Figure 4$), p<0.001$.

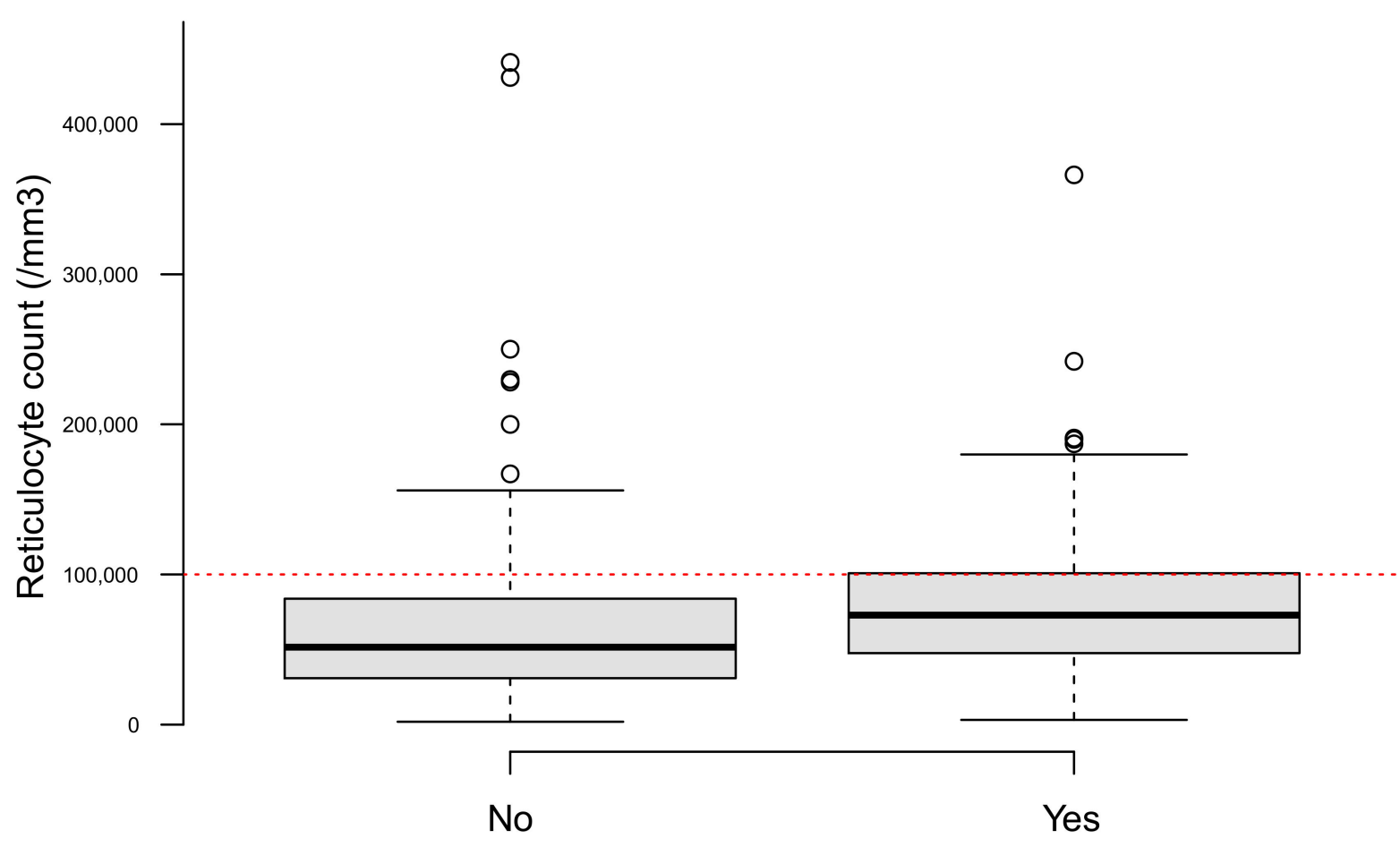

\section{Bleeding}

Figure 4. Boxplots showing the reticulocyte count depending on whether a bleeding was observed in the ED $(N=251)$.

\subsection{Transfusion}

Patients received 1 RBC pack in $72(14.1 \%)$ cases, 2 packs in $333(65 \%)$ cases, 3 packs in $70(13.7 \%)$ cases, and more than 3 packs in $37(7.2 \%)$ cases (17 were missing data). After ED transfusion, $\mathrm{Hb}$ was obtained for 453 (85.6\%) patients and was 8.9 (8.1-9.8) g/dL. Figure 5 shows the pretransfusion $\mathrm{Hb}$ level and the transfusion yield (difference of $\mathrm{Hb}$ level after and before transfusion) depending on the number of transfused RBC packs.

One hundred and three patients (19.5\%) were overtransfused (post-transfusion $\mathrm{Hb}$ level $\geq 10 \mathrm{gr} / \mathrm{dL}$ ). Those patients more frequently had coronary artery disease, hypertension, and chronic heart failure than the whole cohort and received 2 RBC packs in $68(68 \%)$ and more than 2 RBC packs in $22(22 \%)$ cases (Table 3).

The pre-and post-transfusion $\mathrm{Hb}$ levels were similar regardless of the presence of a life-threatening condition, a history of coronary artery disease and whether acute bleeding was observed in the ED (Figure 6, Supplementary Table S1).

The emergency physician justified the need for urgent transfusion by the presence of signs of poor tolerance (dyspnea, shock, altered mental status, dizziness, fatigue) in 198 (37.4\%) cases, the presence of active bleeding in $72(13.6 \%)$ cases, a history of coronary artery disease in $19(3.6 \%)$ cases, the rapid onset of anemia in 14 (2.6\%) cases, post chemotherapy aplasia in $13(2.5 \%)$ cases, and a low pre-transfusion $\mathrm{Hb}$ level in $7(1.3 \%)$ cases. The transfusion motive was not notified in the ED medical chart for $206(38.9 \%)$ patients. Among the 225 patients with a pre-transfusion $\mathrm{Hb}$ level $\geq 7 \mathrm{~g} / \mathrm{dL}$, only $33(14.7 \%)$ were at low risk. 

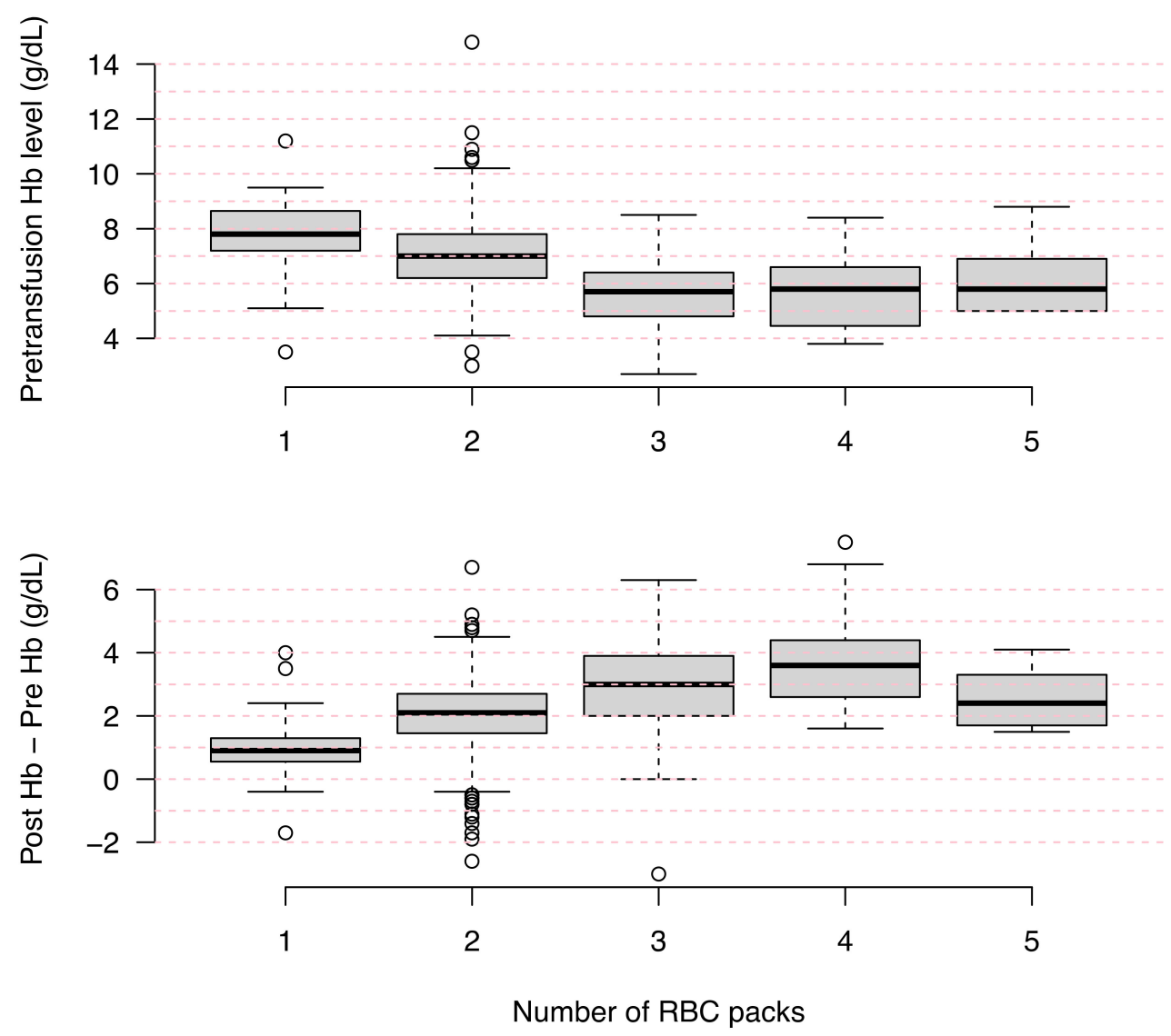

Figure 5. Boxplots of the pretransfusion $\mathrm{Hb}$ level and the $\mathrm{Hb}$ difference before and after transfusion depending on the number of transfused red blood cell packs in the $\operatorname{ED}(N=512)$.

Table 3. Characteristics of patients that were overtransfused with red blood cells (post-transfusion $\mathrm{Hb}$ level $\geq 10 \mathrm{gr} / \mathrm{dL}$ ) in the ED.

\begin{tabular}{|c|c|c|c|}
\hline Variable & & & Missing Data \\
\hline$N$ & 103 & & \\
\hline Female gender, $n(\%)$ & 63 & $(61.2)$ & 0 \\
\hline Age (years), median (IQR) & 80 & $(66-88)$ & 0 \\
\hline Coronary artery disease, $n(\%)$ & 40 & $(39.2)$ & 1 \\
\hline Hypertension, $n(\%)$ & 52 & $(51.0)$ & 1 \\
\hline Chronic heart failure, $n(\%)$ & 22 & $(21.6)$ & 1 \\
\hline Chronic anemia, $n(\%)$ & 34 & $(40.5)$ & 19 \\
\hline Malignancy, $n(\%)$ & 36 & $(35.6)$ & 2 \\
\hline Hb POCT, median (IQR) & 7.5 & $(6.5-9.0)$ & 46 \\
\hline Tachycardia $(\geq 100 / \mathrm{bpm}), n(\%)$ & 32 & $(32.0)$ & 3 \\
\hline Life-threatening condition, $n(\%)$ & 8 & $(31.1)$ & 0 \\
\hline Any bleeding observed in the ED, $n(\%)$ & 8 & $(50.5)$ & 0 \\
\hline Pre-transfusion $\mathrm{Hb}$ level, median (IQR) & 7.8 & $(6.9-8.6)$ & 1 \\
\hline Number of RBC pack, $n(\%)$ & & & 3 \\
\hline 1 & 10 & $(10.0)$ & \\
\hline 2 & 68 & $(68.0)$ & \\
\hline 3 & 9 & $(9.0)$ & \\
\hline 4 & 12 & $(12.0)$ & \\
\hline 5 & 1 & $(1.0)$ & \\
\hline Adverse event, $n(\%)$ & 1 & $(1.0)$ & 0 \\
\hline ICU during hospital stay, $n(\%)$ & 9 & $(10.2)$ & 15 \\
\hline Length of hospital stay, median (IQR) & 2 & $(1-8)$ & 29 \\
\hline Hospital death, $n(\%)$ & 1 & $(1.1)$ & 15 \\
\hline
\end{tabular}




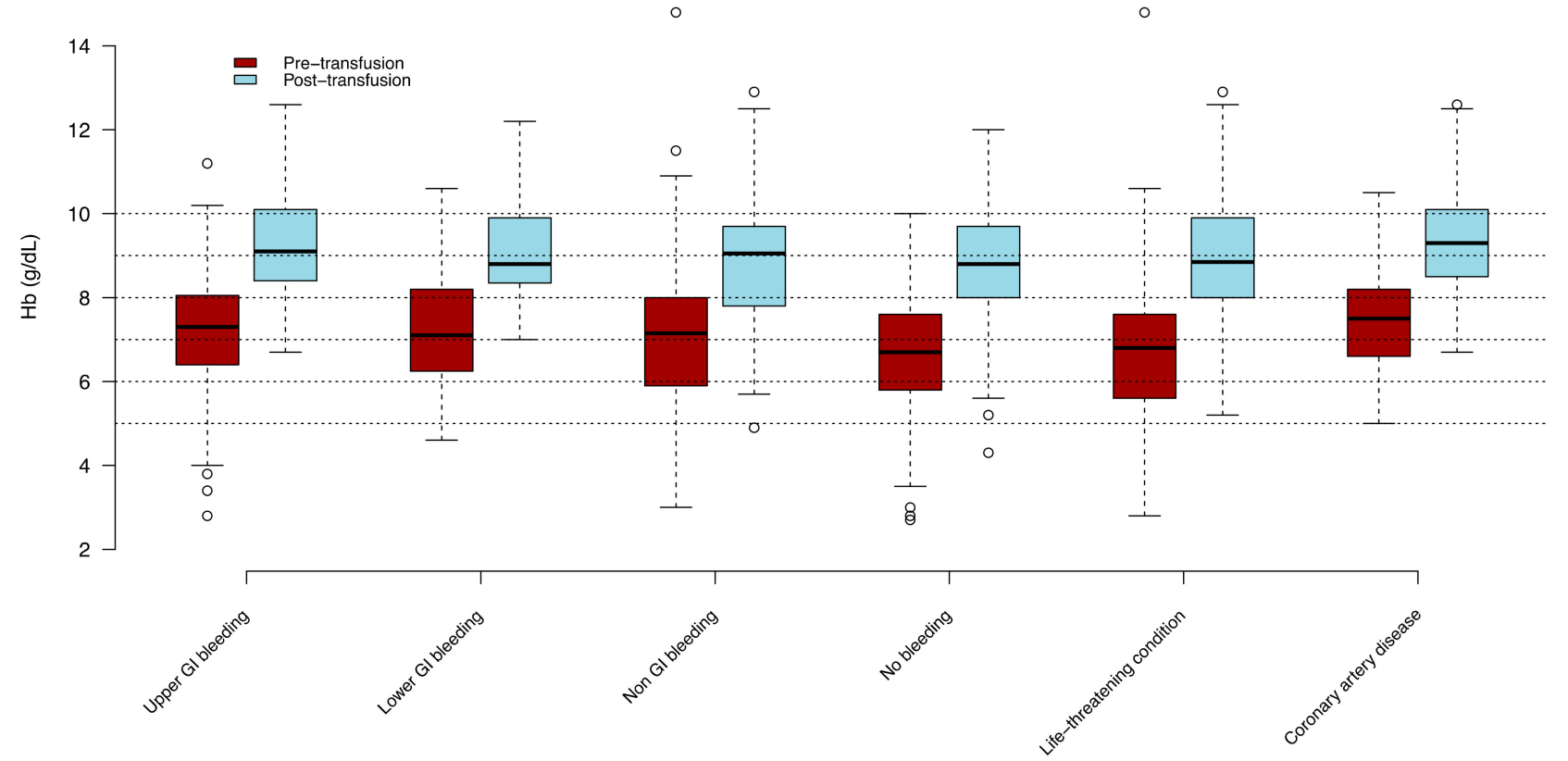

Figure 6. Boxplots of the pre-transfusion and post-transfusion $\mathrm{Hb}$ level in patients depending on the presence or absence of acute bleeding in the ED, a life-threatening condition (shock, dyspnea, altered mental status), and a history of coronary artery disease.

The results of the bivariate and the multivariate analysis are presented in Supplementary Table S2. In the multivariable logistic regression, after adjusting for patient clinical severity, variables that were associated with a higher pre-transfusion $\mathrm{Hb}$ level $(\geq 8 \mathrm{~g} / \mathrm{dL})$ for transfusion were a history of coronary artery disease (OR: 2.09; 95\% CI: $1.29-3.41$ ), the presence of acute bleeding in the ED (OR: $2.44 ; 95 \%$ CI: $1.53-3.94)$, and an older age (OR: 1.02/year; 95\% CI: 1.01-1.04).

\subsection{Adverse Events}

Eight (1.5\%) adverse events were reported in the hospital medical files, among which were six cases of pulmonary edema, one case of hemolysis, and one episode of high blood pressure. Patients that experienced pulmonary edema after RBC transfusion were $\geq 63$ years old, had a history of hypertension and had mostly a life-threatening condition (Supplementary Table S3). None of these patients were admitted to the ICU or died during hospital stay.

\subsection{Outcomes}

After visiting the ED, 448 (84.7\%) were admitted to the ED short stay unit. Among those patients, $130(29 \%)$ stayed less than $24 \mathrm{~h}$ before being discharged home. Other patients were admitted to wards in $49(9.3 \%)$ cases, to the operating room in $1(0.2 \%)$ case, and transferred to another hospital in $2(0.4 \%)$ cases (1 was missing data). Forty-nine $(9.3 \%)$ were admitted to the ICU during hospital stay, among which $28(57.1 \%)$ were admitted directly from the ED. The length of hospital stay was 4 (1-11) days. At hospital discharge, $335(77.2 \%)$ patients were discharged home, $76(17.5 \%)$ were transferred to another hospital and $21(4.8 \%)$ were deceased (97 missing data).

\section{Discussion}

In our study, a patient was transfused with RBC in the ED every one or two days. Acute bleeding was observed in half of the cases, $30 \%$ had a life-threatening condition, and $40 \%$ had chronic anemia. The transfusion motive was not notified in the ED medical chart for almost $40 \%$ of the patients. Pre-transfusion $\mathrm{Hb}$ level was $6.9 \mathrm{~g} / \mathrm{dL}$ in median and was similar regardless of clinical stability or whether or not acute bleeding was observed. 
Acute bleeding, a history of coronary artery disease, and older age were associated with a higher pre-transfusion $\mathrm{Hb}$ level $(\geq 8 \mathrm{~g} / \mathrm{dL}$ ) for transfusion.

If approximatively 1500 patients are transfused each day in France, the prevalence of RBC transfusion in the ED is not known. Langlais et al. assessed the appropriateness of RBC transfusion in the ED of an academic hospital in France before and after the implementation of a protocol [12]. Over one year, 228 patients were transfused, which was similar to the number of transfused patients in our study. It is possible that the prevalence of RBC transfusions in non-academic EDs differs from what we observed, and also may depend on some local specific organization, specifically for oncologic patients needing iterative transfusions. If the prevalence of RBC transfusions in the ED seems low, it is important to realize that it is a daily issue. Furthermore, this procedure can be extremely time-consuming for nurses and needs close monitoring to avoid adverse events. Other studies in the USA, UK, and Spain showed similar numbers of daily transfused patients in the ED [13-17].

Bleeding seems to be the main reason for transfused patients to seek emergency care as almost half of the patients had acute bleeding observed in the ED. In other studies focusing on ED transfusion, gastro-intestinal bleeding was one of the most frequent indication for RBC transfusion in the ED [12-15,17,18]. Contrarily to some other studies [13,19], bleeding due to trauma was scarce in our study. This may be explained by the French pre-hospital emergency care organization where a Mobile Intensive Care Unit, staffed by an emergency physician, can be sent on scene for pre-hospital medical assistance when a life-threatening condition is suspected. Thus, patients with major trauma are transported directly to the ICU without going through the ED.

Many of these transfusions occurred for patients with chronic diseases such as cancer, hematological disease, and iron or vitamin deficiency. Cancer exposes patients to multiple complications that can make them seek emergency care [20]. Some of these complications, such as bleeding, inflammation, cytotoxic chemotherapy, or bone marrow infiltration, may cause anemia needing transfusion. In other studies focusing on RBC transfusion in the ED, patients with cancer and hematological disease ranged from $20 \%$ to $45 \%$ [12,15,18,19,21,22]. In our study, patients were frequently admitted for less than $24 \mathrm{~h}$ raising the question of the appropriate use of ED for transfusion motive. Furthermore, Barr et al. showed that patients being treated for cancer had a higher risk of inappropriate transfusion in the ED with higher $\mathrm{Hb}$ thresholds [18].

It is very difficult to assess retrospectively the appropriateness of $\mathrm{RBC}$ transfusion but it seems that the pre-transfusion $\mathrm{Hb}$ levels used in the ED were rather low and in accordance with the restrictive thresholds recommended by the French guidelines [2]. However, assessing appropriateness only based on the threshold may not be relevant because in the emergency setting, those thresholds are often balanced by the clinical context such as hemodynamic instability, the acuteness and tolerance of anemia or, in case of acute bleeding, the importance of blood loss [23]. Furthermore, the patient $\mathrm{Hb}$ level is not known at arrival to the ED or may be falsely normal in the first hours of acute bleeding. Thus, an emergency physician may decide to transfuse a critically ill patient based only on physical examination. Surprisingly, in our study, the thresholds did not seem to be influenced by the clinical context and were similar whether or not there was acute bleeding or severity signs. In addition, deciding whether to transfuse a clinically stable patient is not a binary decision based solely on the $\mathrm{Hb}$ level but depends sometimes on subjective signs such as the tolerance of anemia. Patients may not have obvious life-threatening conditions or tachycardia but report extreme fatigue or exertional dyspnea that could justify transfusion, even above recommended thresholds, especially in elderly patients or in patients with coronary artery disease. Two studies assessed the appropriateness of RBC transfusion in the ED and showed a rate of inappropriate transfusions over 20\% [17,18]. In these studies, patients with a higher pre-transfusion $\mathrm{Hb}$ level, chronic anemia, that were being being treated for cancer, or that were younger carried a higher risk of inappropriate transfusion, as well as treatment taking place in small non-teaching hospitals and the 
prescribing physicians having lower expertise. Thus, implementing transfusion protocols in the ED may reduce the rate of those inappropriate transfusions $[16,19]$.

Another interesting finding was that almost $20 \%$ of the patients seemed to have been overtransfused with a post-transfusion $\mathrm{Hb}$ level $\geq 10 \mathrm{gr} / \mathrm{dL}$. Given the number of RBC packs that those patients received, maybe a more graduated transfusion strategy (e.g., prescribing RBC packs one by one, instead of two or more from the beginning) could have been more appropriate and reduced the risk of overtransfusion, even if it is difficult to ascertain it retrospectively.

Among other findings, we showed that the $\mathrm{Hb}$ POCT results at ED arrival appeared to be concordant with the pre-transfusion $\mathrm{Hb}$ levels measured by laboratory $\mathrm{CBC}$. However, when regarding an $\mathrm{Hb}$ level threshold of $7 \mathrm{~d} / \mathrm{dL}$, results were discordant for $48(19 \%)$ patients. This is consistent with other studies in the ED [24-26]. Furthermore, the percentage error of $37 \%$ was above the admitted threshold of $30 \%$ which is defined a priori to indicate clinically useful agreement [27]. The reticulocyte count was significantly higher when acute bleeding was observed. Nevertheless, the difference between both groups was small with an important distribution overlap.

If adverse events seemed relatively scarce in the $\mathrm{ED}$, the number of pulmonary edemas was higher than those reported in France by the EFS in 2018; 10 for 100,000 RBC packs transfused. On one hand, those patients that experienced pulmonary edema were mostly aged and with a history of hypertension but, on the other hand, they seemed to need urgent transfusion in the light of their low pre-transfusion $\mathrm{Hb}$ level and their risk category. However, transfusion must be cautiously given to elderly patients with a history of chronic cardiac diseases.

\section{Limitations}

Our study has several limitations. First, we were unable to assess retrospectively the appropriateness of RBC transfusions because almost $40 \%$ of the patients had no justification to the transfusion in the ED medical file. Thus, deducing the need for urgent transfusion based only on the data from the ED medical file seemed hazardous. In addition, the retrospective data collection certainly introduced some interpretation bias. Secondly, our study enrolled all the patients that were transfused with RBC in the participating EDs but did not consider patients with anemia that were not transfused. Therefore, interpreting the pre-transfusion $\mathrm{Hb}$ level according to recommendations may be spurious because we cannot say how many patients that were not transfused should have been.

\section{Conclusions}

In our study, RBC transfusion in the ED was an everyday concern and involved patients with heterogeneous medical situations and severity. Therefore, the $\mathrm{Hb}$ thresholds recommended by the guidelines may be difficult to apply in the ED advocating for specific recommendation in this setting. Nevertheless, the pre-transfusion $\mathrm{Hb}$ level was rather restrictive and acute bleeding, a history of coronary artery disease, and older age seemed to be associated with a higher pre-transfusion $\mathrm{Hb}$ level $(\geq 8 \mathrm{~g} / \mathrm{dL})$. A prospective larger study including patients attending ED for transfusion but also with anemia without being transfused is warranted.

Supplementary Materials: The following are available online at https:/ / www.mdpi.com/article / 10.3390/jcm10112475/s1, Table S1: Pre- and post-transfusion hemoglobin (Hb) level in the ED (median [interquartile range] $\mathrm{g} / \mathrm{dL}$ ) depending on the bleeding group, the presence of a life-threatening condition (shock, dyspnea, or altered mental status) or a history of coronary artery disease, Table S2: Bivariate and multivariate analyses to identify variables that were associated with a higher threshold for transfusion (pre-transfusion $\mathrm{Hb}$ level $\geq 8 \mathrm{~g} / \mathrm{dL}$ ). In order to adjust for patient severity, the variables that referred to life-threatening conditions and tachycardia on arrival were forced into the model, Table S3: Characteristics of the 6 patients that experienced pulmonary edema after ED RBC transfusion. 
Author Contributions: Conception and design: O.P., D.G., R.B. and F.P.; provision of study materials of patients: O.P., A.C., D.A.G., Y.Y., A.A., P.G., S.C., M.-C.R., A.-L.F.-P., B.V., S.B., H.G. and A.F.; collection and assembly of data: O.P., R.B., D.G. and A.C.; data analysis and interpretation: O.P., D.A.G. and R.B.; manuscript writing: O.P., A.F., F.P. and J.-P.F. All authors have read and agreed to the published version of the manuscript.

Funding: This research received no external funding.

Institutional Review Board Statement: The study was approved by the Institutional Review Board of the Comité d'Evaluation de l'Ethique des projets de Recherche Biomédicale (CEERB) Paris-Nord $n^{\circ}$ 2019-023.

Informed Consent Statement: Patient consent was waived due to the retrospective anonymized data.

Data Availability Statement: The data presented in this study are available on request from the corresponding author.

Acknowledgments: The authors thank Anne Claire Leprêtre and Frédéric Le Moine from the EFS of the Saint-Louis hospital (AP-HP) for their valuable help, and the Etablissement Français du Sang (EFS) for their support.

Conflicts of Interest: All authors declare no potential conflict of interest related to the study.

\section{References}

1. Hillenkamp, J.Z.; Wolfson, A.B. Liberal vs Restrictive Hemoglobin Levels as Thresholds for Blood Transfusions. Acad. Emerg. Med. 2021, 28, 593-594. [CrossRef] [PubMed]

2. Haute Autorité de Santé. Transfusion de Globules Rouges Homologues: Produits, Indications Alternatives. Rapport d'activité de l’hémovigilance 2018. 2014. Available online: https://ansm.sante.fr/var/ansm_site/storage/original/application/94eaed87fcb1 d3c9d2187f4945256875.pdf (accessed on 1 November 2020).

3. Mueller, M.M.; Van Remoortel, H.; Meybohm, P.; Aranko, K.; Aubron, C.; Burger, R.; Carson, J.L.; Cichutek, K.; De Buck, E.; Devine, D.; et al. Patient Blood Management: Recommendations From the 2018 Frankfurt Consensus Conference. JAMA 2019, 321, 983-997. [CrossRef] [PubMed]

4. Thiebaud, P.C.; Yordanov, Y.; Galimard, J.E.; Raynal, P.A.; Beaune, S.; Jacquin, L.; Ageron, F.X.; Pateron, D.; Initiatives de Recherche aux Urgences Group. Management of upper gastrointestinal bleeding in emergency departments, from bleeding symptoms to diagnosis: A prospective, multicenter, observational study. Scand J. Trauma Resusc. Emerg. Med. 2017, 25, 78. [CrossRef] [PubMed]

5. Thiebaud, P.C.; Yordanov, Y.; Galimard, J.E.; Naouri, D.; Brigant, F.; Truchot, J.; Moustafa, F.; Pateron, D.; aux Urgences, T.I Suspected lower gastrointestinal bleeding in emergency departments, from bleeding symptoms to diagnosis. Am. J. Emerg. Med. 2019, 37, 772-774. [CrossRef]

6. Vincent, J.L.; Baron, J.F.; Reinhart, K.; Gattinoni, L.; Thijs, L.; Webb, A.; Meier-Hellmann, A.; Nollet, G.; Peres-Bota, D.; ABC (Anemia and Blood Transfusion in Critical Care) Investigators. Anemia and blood transfusion in critically ill patients. JAMA 2002, 288, 1499-1507. [CrossRef]

7. Cable, C.A.; Razavi, S.A.; Roback, J.D.; Murphy, D.J. RBC Transfusion Strategies in the ICU: A Concise Review. Crit. Care Med. 2019, 47, 1637-1644. [CrossRef] [PubMed]

8. Villanueva, C.; Colomo, A.; Bosch, A.; Concepción, M.; Hernandez-Gea, V.; Aracil, C.; Graupera, I.; Poca, M.; Alvarez-Urturi, C.; Gordillo, J.; et al. Transfusion strategies for acute upper gastrointestinal bleeding. N. Engl. J. Med. 2013, 368, 11-21. [CrossRef]

9. Jairath, V.; Kahan, B.C.; Gray, A.; Doré, C.J.; Mora, A.; James, M.W.; Stanley, A.J.; Everett, S.M.; Bailey, A.A.; Dallal, H.; et al. Restrictive versus liberal blood transfusion for acute upper gastrointestinal bleeding (TRIGGER): A pragmatic, open-label, cluster randomised feasibility trial. Lancet 2015, 386, 137-144. [CrossRef]

10. Maher, P.J.; Khan, S.; Karim, R.; Richardson, L.D. Determinants of empiric transfusion in gastrointestinal bleeding in the emergency department. Am. J. Emerg. Med. 2020, 38, 962-965. [CrossRef]

11. Ley, E.J.; Liou, D.Z.; Singer, M.B.; Mirocha, J.; Melo, N.; Chung, R.; Bukur, M.; Salim, A. Emergency department blood transfusion: The first two units are free. J. Surg. Res. 2013, 184, 546-550. [CrossRef]

12. Langlais, M.L.; Dargère, M.; Le Niger, C.; Goetghebeur, D. Pertinence des prescriptions de concentrés de globules rouges par le médecin urgentiste avant et après la mise en place d'un protocole [Appropriate use of red blood cell transfusion in the emergency department before and after a specific protocol]. Transfus. Clin. Biol. 2019, 26, 38-47. [CrossRef]

13. Beckwith, H.; Manson, L.; McFarlane, C.; Reed, M.J. A review of blood product usage in a large emergency department over a one-year period. Emerg. Med. J. 2010, 27, 439-442. [CrossRef] [PubMed]

14. Díaz, M.Q.; Borobia, A.M.; Erce, J.A.; Maroun-Eid, C.; Fabra, S.; Carcas, A.; Frías, J.; Muñoz, M. USEES-URG Research Group. Appropriate use of red blood cell transfusion in emergency departments: A study in five emergency departments. Blood Transfus. 2017, 15, 199-206.

15. Beyer, A.; Rees, R.; Palmer, C.; Wessman, B.T.; Fuller, B.M. Blood product transfusion in emergency department patients: A case-control study of practice patterns and impact on outcome. Int. J. Emerg. Med. 2017, 10, 5. [CrossRef] [PubMed] 
16. Reed, M.J.; Kelly, S.L.; Beckwith, H.; Innes, C.J.; Manson, L. Successful implementation of strategies to transform Emergency Department transfusion practice. BMJ Qual. Improv. Rep. 2013, 2, u201055.w690. [CrossRef]

17. Quintana-Díaz, M.; Andrés-Esteban, E.M.; Sánchez-Serrano, J.; Martínez-Virto, A.; Juárez-Vela, R.; García-Erce, J.A. Transfusions in the Emergency department: More than a blood transfusion. Rev. Clin. Esp. 2020, 220, 393-399. [CrossRef]

18. Barr, P.J.; Donnelly, M.; Cardwell, C.R.; Parker, M.; Morris, K.; Bailie, K.E. The appropriateness of red blood cell use and the extent of overtransfusion: Right decision? Right amount? Transfusion 2011, 51, 1684-1694. [CrossRef]

19. Alavi-Moghaddam, M.; Bardeh, M.; Alimohammadi, H.; Emami, H.; Hosseini-Zijoud, S.M. Blood Transfusion Practice before and after Implementation of Type and Screen Protocol in Emergency Department of a University Affiliated Hospital in Iran. Emerg. Med. Int. 2014, 2014, 316463. [CrossRef] [PubMed]

20. Peyrony, O.; Fontaine, J.P.; Beaune, S.; Khoury, A.; Truchot, J.; Balen, F.; Vally, R.; Schmitt, J.; Ben Hammouda, K.; Roussel, M.; et al. EPICANCER-Cancer Patients Presenting to the Emergency Departments in France: A Prospective Nationwide Study. J. Clin. Med. 2020, 9, 1505. [CrossRef] [PubMed]

21. Lee, J.H.; Kim, D.H.; Kim, K.; Rhee, J.E.; Kim, T.Y.; Jo, Y.H.; Lee, J.H.; Suh, G.J.; Hwang, S.S.; Lee, C.C.; et al. Predicting change of hemoglobin after transfusion in hemodynamically stable anemic patients in emergency department. J. Trauma. 2010, 68, 337-341. [CrossRef]

22. Moretti, K.; Marqués, C.G.; Garbern, S.; Mbanjumucyo, G.; Uwamahoro, C.; Beaudoin, F.L.; Amanullah, S.; Gjelsvik, A.; Aluisio, A.R. Transfusion, mortality and hemoglobin level: Associations among emergency department patients in Kigali, Rwanda. Afr. J. Emerg. Med. 2020, 10, 68-73. [CrossRef] [PubMed]

23. Long, B.; Koyfman, A. Red Blood Cell Transfusion in the Emergency Department. J. Emerg. Med. 2016, 51, 120-130. [CrossRef] [PubMed]

24. Osborn, Z.T.; Villalba, N.; Derickson, P.R.; Sewatsky, T.P.; Wager, A.P.; Freeman, K. Accuracy of Point-of-Care Testing for Anemia in the Emergency Department. Respir. Care 2019, 64, 1343-1350. [CrossRef] [PubMed]

25. Van de Louw, A.; Lasserre, N.; Drouhin, F.; Thierry, S.; Lecuyer, L.; Caen, D.; Tenaillon, A. Reliability of HemoCue in patients with gastrointestinal bleeding. Intensive Care Med. 2007, 33, 355-358. [CrossRef]

26. Dolscheid-Pommerich, R.C.; Dolscheid, S.; Grigutsch, D.; Stoffel-Wagner, B.; Graeff, I. Comparability of Point-of-Care versus Central Laboratory Hemoglobin Determination in Emergency Patients at a Supra-Maximal Care Hospital. PLoS ONE 2016, 11, e0166521. [CrossRef]

27. Critchley, L.A.; Critchley, J.A. A meta-analysis of studies using bias and precision statistics to compare cardiac output measurement techniques. J. Clin. Monit. Comput. 1999, 15, 85-91. [CrossRef] 